\title{
High iodine intake by preschool children in Miyagi prefecture, Japan
}

\author{
Haruo Nakatsuka $\cdot$ Takao Watanabe $\cdot$ Shinichiro Shimbo $\cdot$ Hideyuki Sawatari \\ Kana Izumi · Kozue Yaginuma-Sakurai $\cdot$ Masayuki Ikeda
}

Received: 16 January 2014/ Accepted: 4 June 2014/Published online: 28 June 2014

(C) The Japanese Society for Hygiene 2014

\begin{abstract}
Objectives Standard Tables of Food Composition in Japan 2010 (FCT) remain incomplete for iodine contents. This survey was initiated to develop a method to cope with this shortage and to find daily iodine intake of preschool children in Japan.

Methods Data were available for one-day food intake for 296 3- to 6-year-old children (the total cases). 128 samples (the selected cases) were analyzed by ICP-MS for iodine (the measured values). Iodine intake was also calculated using FCT assuming that iodine contents in missing items were zero (the calculated values).

Results Measured and calculated values for the selected 125 cases (after exclusion of 3 extreme cases) gave geometric means (GM) of 117.6 and $101.8 \mu \mathrm{g} / \mathrm{day}$. The measured/calculated ratio in GM, 117.6/101.8 $=1.155$, was applied to the calculated values for total 296 cases to
\end{abstract}

\footnotetext{
H. Nakatsuka

Miyagi University, Taiwacho 981-3298, Japan

T. Watanabe

Tohoku Bunkyo University, Yamagata 990-2316, Japan

S. Shimbo

Kyoto Women's University, Kyoto 605-8501, Japan

H. Sawatari · K. Izumi

Miyagi University of Education, Sendai 980-0845, Japan

K. Yaginuma-Sakurai

Shokei Gakuin University, Miyagi 990-2316, Japan

M. Ikeda ( $\square)$

Kyoto Industrial Health Association (Main Office),

67 Nishinokyo-Kitatsuboicho, Nakagyo-ku,

Kyoto 604-8472, Japan

e-mail: ikeda@hokenkai.jp
}

estimate iodine intake (the estimated values). GM for the estimated value was $175.2 \mu \mathrm{g} /$ day and it was $8.93 \mu \mathrm{g} / \mathrm{kg} /$ day after adjustment for body weight for 296 children. There was no significant difference between boys and girls. Discussion The GM values for both the measured and estimated values ( $n=125$ pairs) were $117.6 \mu \mathrm{g} /$ day. The agreement suggested that the factor employed, 1.155, was proper and adequate. Literature survey suggested that values on a body weight basis were comparable between the children and adults in Japan. The levels were higher than levels in east Asian countries.

Conclusions A correction method was developed for estimation of daily dietary iodine intake. The iodine intake level for preschoolers was comparable to levels for adult population.

Keywords Children - Dietary intake $\cdot$ Food composition tables - Inductively coupled plasma-mass spectrometry · Iodine $\cdot$ Japanese

\section{Introduction}

Iodine (I) is a unique essential element in the sense that insufficient intake among general population may cause endemic goiter whereas excess intake may induce thyroid dysfunction [1]. Administration of potassium iodide has been discussed at the time of nuclear emergency to reduce risk of accumulation of radioactive iodine in thyroid [2-5], but positive association between seaweed consumption and increased risk of thyroid cancer is also discussed [6].

As to be discussed later in detail, it is considered that dietary iodine intake is high among general Japanese population. For example, Nagataki [7] and Muramatsu [8] estimated that dietary intake of iodine was $1.1-1.2 \mathrm{mg} / \mathrm{day}$, and Imaeda et al. [9] estimated 312 and $413 \mu \mathrm{g} /$ day for 
'usual intake [10]' of men and women, respectively. Nevertheless, the quantitative information on dietary iodine intake among Japanese population is still insufficient [11] and the information is further limited on the intake by children [12]. Incomplete listing of iodine contents in food materials in Standard Tables of Food Composition in Japan 2010 (FCT) [13], even after the latest addition to the FCT [14], makes it difficult to obtain correct estimates for children as well as adult population.

The present study was initiated to measure dietary iodine intake among 3- to 6-year-old preschool children, taking advantage of recently published food intake records [15-17]. For this purpose, two methods were employed. One is instrumental analysis using inductively coupled plasma-mass spectrometry (ICP-MS) after alkali digestion. ICP-MS [18] has been gaining popularities in recent years as a tool to measure iodine in various biological materials including foods [19-23]. The other is FCT-based estimation. The latest version (2010 version) of Japanese FCT (in combination with the latest additions and corrections) lists up, for the first time in a series of the FCT publications, iodine contents in various (although not all) food items consumed by Japanese population [13, 14]. The iodine content values will make it possible to estimate dietary intake of iodine using the FCT.

The results of the analyses will be presented in this article to show distribution pattern of daily iodine intake, and to report dietary intake level of iodine among Japanese children. A procedure will be proposed in the present article to estimate daily iodine intake from FCT-based calculated values. The estimated daily iodine intake for preschoolers will be presented in comparison with levels for adult population in Japan and east Asian countries.

\section{Materials and methods}

\section{Ethical issues}

The study protocol was approved by the Ethics Committee of Miyagi University, Japan. Each and all of guardians of the participating children provided informed consents in writing.

Study participants and food duplicate collections

The participants were apparently healthy 160 boys and 136 girls (296 children in total) from 15 kindergartens in Miyagi prefecture in north-eastern Japan. The children were 3-6 years old, and their body weights were measured and recorded. The demographic characteristics were described in detail previously [15-17], and are summarized in Table 1. Nutrient intakes were also reported in these
Table 1 Demographic parameters

\begin{tabular}{lllllll}
\hline Sex & Age & \multicolumn{2}{l}{ Total group } & \multirow{2}{l}{$\begin{array}{l}\text { Selected group } \\
\text { a }\end{array}$} \\
\cline { 3 - 5 } & & No. & \multicolumn{2}{l}{ Bodyweight $(\mathrm{kg})$} & \\
\cline { 3 - 5 } & & & AM & Min. & Max. & \\
\hline Boys & 3 & 9 & 16.6 & 15.1 & 18.1 & 1 \\
& 4 & 30 & 18.2 & 13.3 & 27.0 & 16 \\
& 5 & 74 & 19.9 & 14.0 & 33.9 & 25 \\
& 6 & 47 & 23.2 & 15.6 & 35.2 & 29 \\
& Sum & 160 & & & & 71 \\
Girls & 3 & 4 & 14.2 & 13.1 & 15.5 & 1 \\
& 4 & 32 & 18.0 & 13.5 & 27.3 & 14 \\
& 5 & 60 & 19.8 & 14.9 & 36.3 & 24 \\
& 6 & 40 & 20.7 & 15.6 & 28.1 & 18 \\
& Sum & 136 & & & & 57 \\
Total & & 296 & & & & 128 \\
\hline
\end{tabular}

a Selected for instrumental analysis for iodine intake; out of the 128 cases, 3 cases were excluded as extreme cases

articles [15-17]. Each of the children submitted 24-hour food duplicate samples [24]. Foods collected from the food duplicate samples were identified in reference to the items in the FCT $[13,14]$. The item number and the weight of each food item were recorded following the procedures detailed previously [15-17]. Each of the food duplicate samples was then homogenized using a blender [15-17].

Instrumental analysis for iodine (measured values)

Due to limitations in analysis capacity, it was not possible to analyze all food duplicate homogenate samples. Thus, 6 kindergartens (with 128 attending children) were identified out of the 16 kindergartens by random selection, and the samples from the 128 children were subjected to the instrumental analysis. The analyses were conducted after the study of Fecher et al. [18] and Ministry of Education, Culture, Sports, Science and Technology, Japan [25]. In practice, a portion of the homogenate $(2.5 \mathrm{~g})$ was wetdigested under alkaline condition with $50 \mathrm{ml}$ of $0.5 \%$ tetramethylammonium hydroxide (TMAH) by heating overnight $(8-12 \mathrm{~h})$ at $60{ }^{\circ} \mathrm{C}$ in a polypropylene vessel with a gas-tight screw cap. The digest was subjected to instrumental analysis after centrifugation to remove solid materials.

The instrument used was an inductively coupled plasmamass spectrometer (Model: $7700 \times$ ) from Agilent Technologies, Santa Clara, California, USA. The instrument was operated under 'no gas mode' (with no use of collision/reaction gas), and tellurium 125 (or tellurium 128) was used as an internal standard. Addition of tellurium internal standard solution was carried out by means of on-line method. 
Under the operation conditions, the recovery in comparison with two reference materials of NIST 1548a (Reference value for I; $0.759 \mathrm{ppm}$ ) and NIES No. 27 (Reference value for I; $1.9 \mathrm{ppm}$ ) was $0.62 \mathrm{ppm}(82 \%)$ and $1.84 \mathrm{ppm}(97 \%)$, respectively. The relative standard deviations $(n=10)$ were 2.6 and $3.8 \%$. The LOD and LOQ were estimated to be $0.1-0.3 \mathrm{ppb}$ and $0.3-1 \mathrm{ppb}$, respectively.

Food composition table-based calculation of the dietary iodine intake (calculated values)

The Standard Tables of Food Composition in Japan 2010 (FCT [13], supplemented by the latest additions and corrections [14]), contain 1,878 food items, of which iodine content data are available for 518 food items $(27.6 \%)$. The coverage by food group vary with a high of $51.4 \%$ for Group 5 (Nuts and seeds) and a low of $16.0 \%$ for both Group 11 (Fishes and shellfishes) and Group 12 (Meats). For Group 9 Algae, the expected leading dietary iodine source for Japanese $[8,9]$, the iodine content values were available for 18 items in a total of 47 items (the coverage; $38.3 \%)$.

The daily iodine intake was calculated from food weights and iodine contents given in the FCT $[13,14]$. In practice, iodine contents were assumed to be zero in food items for which no values were given for iodine contents.

Estimation of daily dietary iodine intake (estimated values)

As detailed above, the iodine contents are not available for many food items in current FCT [13, 14], and assumption of zero iodine content for food items (for which no iodine content values are given) may result in under-estimation. As to be detailed later (also see the footnote under Table 2), the geometric mean for the measured values was $117.6 \mu \mathrm{g} / \mathrm{day}$ in the 125 selected cases and that for the calculated values was $101.8 \mu \mathrm{g} / \mathrm{day}$. The difference between the two values was thought to be due to the missing iodine. The ratio of the measured value GM to the calculated value GM (or $117.6 / 101.8=1.155$ ) was employed to estimate dietary iodine intake from the calculated value, i.e.,

The estimated value $=$ The calculated value $\times 1.155$.

\section{Reagents}

The iodine standard solutions were prepared by dissolving potassium iodide (Wako Pure Chemicals, Osaka, Japan) in $0.5 \%$ TMAH aqueous solution. The standard reference material of typical diet (NIST1548a) was obtained from the National Institute of Standard and Technology (Gaithersburg, USA). The reference material of 'typical Japanese foods' (NIES No. 27) was from the National Institute of Environmental Sciences, Japan (Tsukuba, Japan). TMAH of high purity (with iodine inpurity $<200 \mathrm{ng} / \mathrm{l}$ ) was obtained from Tama Chemicals, Kawasaki, Japan.

\section{Statistical analysis}

As to be described later, the daily intake amount of iodine from diets distributed log-normally. Thus, iodine amount data were logarithmically converted before statistical evaluation by Student's $t$ test, etc. Geometric means (GM) and geometric standard deviations (GSD) together with medians (MED) were taken as representative parameters of the distributions. When necessary, two-way analysis of variance (followed by Scheffe's test) and Smirnov's test for extreme values [25] were employed.

\section{Results}

Distribution patterns of the amounts of iodine intake among 125 selected cases

Measured values were available for 128 cases initially. Application of Smirnov's test for extreme values identified three cases as extremes to be excluded. Thus, further statistical analyses were conducted with remaining 125 cases. Analyses for distribution patterns with the 125

Table 2 Comparison of calculated, estimated and measured values among selected 125 cases

\begin{tabular}{|c|c|c|c|c|c|c|c|c|c|c|c|c|}
\hline & \multirow[t]{2}{*}{ No. } & \multicolumn{3}{|c|}{ Measured values } & \multicolumn{4}{|c|}{ Calculated values } & \multicolumn{4}{|c|}{ Estimated values } \\
\hline & & GM & GSD & MED & GM & $(\%)^{\mathrm{a}}$ & GSD & MED & GM & $(\%)^{\mathrm{a}}$ & GSD & MED \\
\hline Boys & 68 & 110.1 & 2.48 & 81.4 & 95.4 & & 2.51 & 89.6 & 110.2 & & 2.51 & 103.5 \\
\hline Girls & 57 & 127.3 & 2.25 & 109.5 & 110.0 & & 2.59 & 93.5 & 127.2 & & 2.59 & 108.0 \\
\hline Total & 125 & 117.6 & 2.37 & 96.3 & 101.8 & $(86.5)$ & 2.54 & 90.9 & 117.6 & $(100.0)$ & 2.54 & 105.1 \\
\hline
\end{tabular}

GMs and MEDs are in $\mu \mathrm{g} / \mathrm{day}$. GSD s are dimensionless. The ratio of GM for measured values over GM for calculated values: (117.6/ 101.8) $=1.155$

a Percentage of GM values over GM for measured values 
(a)

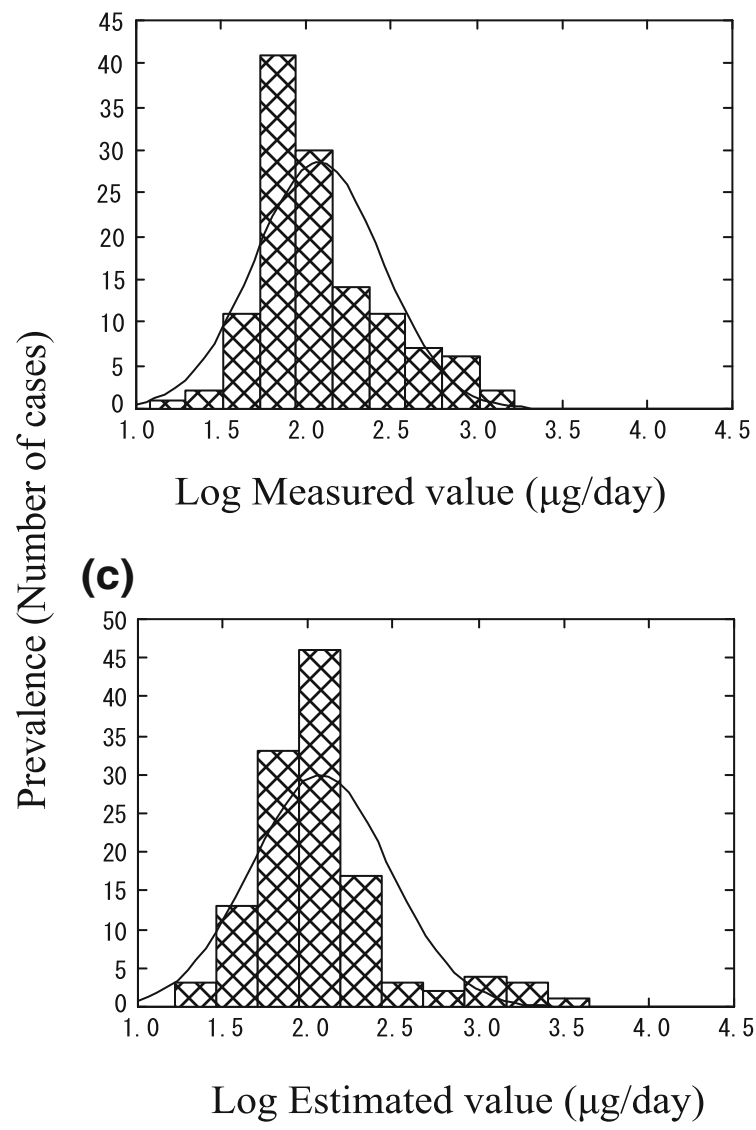

Fig. 1 Distribution histograms of a measure values b calculated values and $\mathbf{c}$ estimated values (after logarithmic conversion) for 125 selected cases. d shows the distribution of a total 296 cases. The

cases (Fig. 1) showed that both measured and calculated values distributed approximately log-normally (Fig. 1a, b and $c$ ).

Comparison of measured values and calculated values, and development of a method for estimated values

Analysis for relation between 125 pairs of logarithm of the measured values and that of the calculated values (Fig. 2) revealed that the pairs correlated significantly with a correlation coefficient of 0.442 ( $p<0.01$ for the coefficient). Nevertheless, GM for calculated values (101.8 $\mu \mathrm{g} /$ day) was smaller than the GM for measured values $(117.6 \mu \mathrm{g} / \mathrm{day})$ ( $p<0.01$ by paired $t$ test); the former was $86.5 \%$ of the latter. When the ratio of $117.6 / 101.8=1.155$ was applied to the calculated values as the compensation for missing iodine items, the application resulted in the GM of $117.6 \mu \mathrm{g} /$ day, which is the same with the GM for the measured values $(117.6 \mu \mathrm{g} /$ day) (Table 2$)$ to suggest that the estimation was adequate. (b)

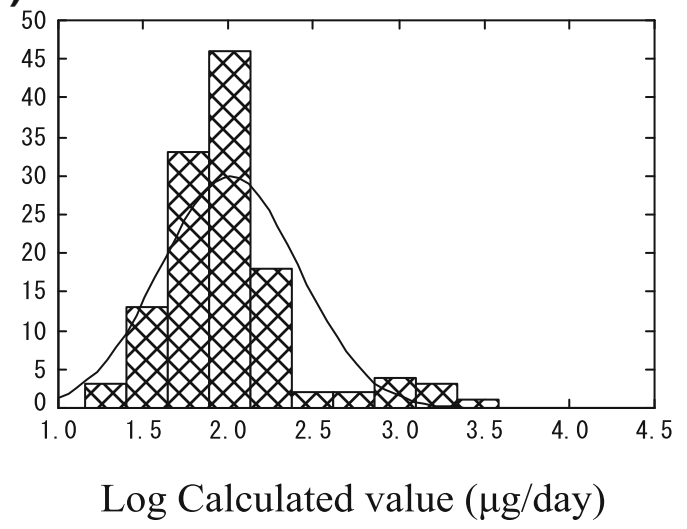

(d)

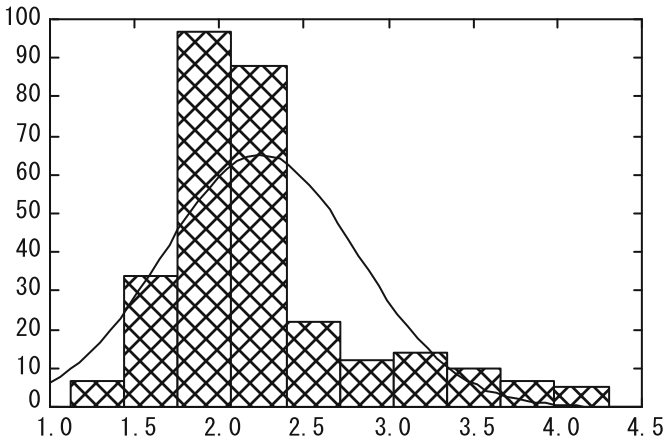

Log Estimated value ( $\mu \mathrm{g} /$ day)

horizontal axes show the values after logarithmic conversion; the values are in $\mu \mathrm{g} /$ day. The curves show normal distribution

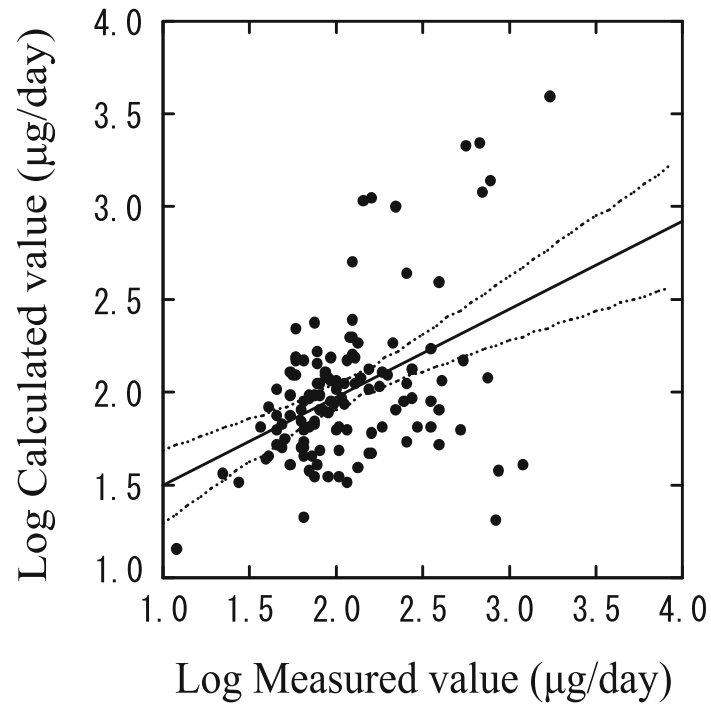

Fig. 2 Correlation between 125 pairs of measured values and calculated values after logarithmic conversion. Each dot shows one case and the line in the middle is a calculated regression line of $Y=1.02+0.48 X$ $(r=0.442, p<0.01)$, where $X$ and $Y$ are $\log$ measured and calculated values (both in $\mu \mathrm{g} / \mathrm{day}$ ), respectively. The dotted curves on both sides of the regression line show the $95 \%$ limit of the means 
Table 3 Estimated daily iodine intake of 296 children; as observed and as corrected for body weight

\begin{tabular}{|c|c|c|c|c|c|c|c|c|c|}
\hline \multirow[t]{2}{*}{ Age } & \multicolumn{3}{|c|}{ Boys } & \multicolumn{3}{|c|}{ Girls } & \multicolumn{3}{|c|}{ Total } \\
\hline & No. & GM & MED & No. & GM & MED & No. & GM & MED \\
\hline \multicolumn{10}{|c|}{ (A) As observed (unit: $\mu \mathrm{g}$ iodine/day) } \\
\hline $3+4$ years & 39 & 257.7 & 128 & 36 & 191.1 & 141 & 75 & 223.2 & 137 \\
\hline 5 years & 74 & 181.7 & 133 & 60 & 142.8 & 114 & 134 & 163.1 & 126 \\
\hline 6 years & 47 & 160.7 & 138 & 40 & 156.2 & 108 & 87 & 158.6 & 123 \\
\hline Total & 160 & 190.9 & 136 & 136 & 158.4 & 116 & 296 & 175.2 & 127 \\
\hline \multicolumn{10}{|c|}{ (B) As corrected for body weight (unit; $\mu \mathrm{g}$ iodine $/ \mathrm{kg}$ body weight $/$ day) } \\
\hline $3+4$ years & 39 & 14.64 & 8.13 & 36 & 11.00 & 7.60 & 75 & 12.76 & 7.66 \\
\hline 5 years & 74 & 9.25 & 6.80 & 60 & 7.34 & 5.93 & 134 & 8.34 & 6.12 \\
\hline 6 years & 47 & 7.02 & 6.08 & 40 & 7.61 & 4.80 & 87 & 7.29 & 5.72 \\
\hline Total & 160 & 9.54 & 6.64 & 136 & 8.26 & 6.05 & 296 & 8.93 & 6.28 \\
\hline
\end{tabular}

Daily iodine intake by age groups

The daily iodine intake was estimated for a total of 296 cases by application of the factor of 1.155 to each of the calculated values, and the estimated values thus obtained were classified by sex and age of the children. As the number of cases of 3-year-old girls was as small as 4, two groups, 3- and 4-year olds, were combined both for boys and for girls (the top half in Table 3). The GM for the estimated iodine intake was $191 \mu \mathrm{g} /$ day for boys, $158 \mu \mathrm{g} /$ day for girls, and $175 \mu \mathrm{g} /$ day for the combination. The intake tended to decrease as a function of age. Application of two-way analysis of variance taking sex and age as two independent variables and log-estimated iodine values as a dependent variable, however, showed that the decrease was statistically insignificant $(p>0.10)$.

Daily iodine intake as adjusted for body weight

It was evident that children became heavier as they grew (Table 1). When the iodine intake was adjusted for body weight, the GM iodine intake was $8.93 \mu \mathrm{g} / \mathrm{kg} /$ day for total children $(9.54 \mu \mathrm{g} / \mathrm{kg}$ body weight/day for boys and $8.26 \mu \mathrm{g} / \mathrm{kg}$ body weight/day for girls) (the bottom half in Table 3). Two-way analysis of variance followed by post hoc test (Scheffe) taking sex (in two categories of boys and girls) and age (in three categories of $3+4$ years, 5 years and 6 years of age) as two independent variables and log (estimated iodine value/kg body weight/day) as a dependent variable disclosed that the difference between boys and girls was insignificant $(p>0.10)$. The difference between the $3+4$ year-old group and the 6-year-old group was significant $(p<0.05)$ whereas no difference was observed between the $3+4$ year-old group and the 5-yearold group or between the 5-year-old group and the 6-yearold group $(p>0.10)$.

\section{Discussion}

It has been reported that dietary intake of iodine in Japan is among the highest groups in the world [27-30]. Nevertheless, information is still insufficient for adult population [11] and further scarce for children [12].

The present analysis showed that the iodine intake by 3 to 6-year-old children is $175 \mu \mathrm{g} /$ day as GM and $127 \mu \mathrm{g} /$ day as MED (the top half in Table 3). When adjusted for body weight, GM and MED values are 8.93 and $6.28 \mu \mathrm{g} /$ $\mathrm{kg} /$ day, respectively (the bottom half in Table 3 ). The factor of 1.155 to convert FCT-based calculated values to the estimated daily intake was considered to be proper and adequate, because the conversion gave the same GM for the estimated values (e.g., $117.6 \mu \mathrm{g} /$ day for boys and girls combined) to the GM for the calculated values $(117.6 \mu \mathrm{g} /$ day) (Table 2). Comparison with the iodine intake recommended by the Ministry of Health, Labour and Welfare, Japan [31] for 3- to 6-year-old children (Table 4) shows that the intake observed among the children is in excess of recommended dietary allowance (RDA; 60-75 $\mu \mathrm{g} /$ day or $3.4-3.7 \mu \mathrm{g} / \mathrm{kg} /$ day) but well below the allowable upper limit (UL) of 350-500 $\mu \mathrm{g} / \mathrm{day}$ or $21.6-22.7 \mu \mathrm{g} / \mathrm{kg} / \mathrm{day}$.

Table 4 Recommended iodine intake

\begin{tabular}{llllll}
\hline Age & Unit & EAR & RDA & UL & BW \\
\hline 3-5 years & $\mu \mathrm{g} /$ day & 45 & 60 & 350 & $16.2 \mathrm{~kg}$ \\
& $\mu \mathrm{g} / \mathrm{kg} /$ day & 2.78 & 3.70 & 21.60 & \\
6-7 years & $\mu \mathrm{g} /$ day & 55 & 75 & 500 & $16.2 \mathrm{~kg}$ \\
& $\mu \mathrm{g} / \mathrm{kg} /$ day & 2.50 & 3.40 & 22.73 & \\
\hline
\end{tabular}

The same value for both boys and girls

$E A R$ estimated average requirement, $R D A$ Recommended dietary allowance, $U L$ Allowable upper limit, $B W$ Standard body weight

Values are cited from Ministry of Health, Labour and Welfare, Japan [31] 
In the following discussion, efforts were made to compare iodine intake on the body weight basis because most of the existing data are for adult population. Findings in selected reports on Japanese population are summarized in Table 5. For example, Tsukada et al. [32] reported their FCT-based observation of $339 \mu \mathrm{g} /$ day for adult Japanese or $5.94 \mu \mathrm{g} / \mathrm{kg} /$ day when adjusted for body weight. Imaeda et al. [9] estimated median (usual day [10] ) iodine intake of 312 and $413 \mu \mathrm{g} /$ day for men and women with average body weights of 62.0 and $52.2 \mathrm{~kg}$, respectively, or 5.0 and $7.9 \mu \mathrm{g} / \mathrm{kg} /$ day. Nagataki [7] and Muramatsu [8], in contrast, gave much greater estimates of 1,200 and 1,100 $\mu \mathrm{g} /$ day, which are equivalent to $19-20 \mu \mathrm{g} / \mathrm{kg} / \mathrm{day}$. The MED by the present study, $6.28 \mu \mathrm{g} / \mathrm{kg} / \mathrm{day}$, is essentially the same with the MED of $6.60 \mu \mathrm{g} / \mathrm{kg} /$ day by Fuse et al. [12] when adjusted for body weight. Thus, the iodine intake by children appears to be comparable to the levels for adult Japanese.

In east Asia, Kim et al. [35] in Korea estimated that the AM iodine intake by adult Koreans was 450.9 and $504.6 \mu \mathrm{g} /$ day; the GM values were 313.7 and $336.8 \mu \mathrm{g} /$ day when GM values were estimated from AM to ASD using the moment method [36], or 5.0 and $7.9 \mu \mathrm{g} / \mathrm{kg} / \mathrm{day}$ with further consideration of 62.0 and $52.2 \mathrm{~kg}$ for average body weight of men and women, respectively. Kim et al. [37] reported $376.5 \pm 281.7 \mu \mathrm{g} /$ day as an $\mathrm{AM} \pm \mathrm{ASD}$ iodine intake by adult Korean men with normal thyroid function. The GM value is $301.5 \mu \mathrm{g} /$ day when the moment method was applied, or $4.3 \mu \mathrm{g} / \mathrm{kg} /$ day when $70 \mathrm{~kg}$ was taken into account for average body weight of 40-year-old men [38]. In Shanghai, China, where table salt was iodized at the level of $29.5 \mathrm{mg} / \mathrm{kg}$, median urinary iodine concentration was $146.7 \mu \mathrm{g} / \mathrm{l}$ [39], which suggests an iodine intake of $3.4 \mu \mathrm{g} / \mathrm{kg} / \mathrm{day}$, when the estimation equation of urinary iodine concentration (UIC: $\mu \mathrm{g} / \mathrm{l}$ in 24-hour urine sample) to daily iodine intake (DII in $\mu \mathrm{g} /$ day $), \quad \mathrm{DII}=\mathrm{UIC} \times 0.0235 \times$ body weight $(\mathrm{kg})$ [40], is applied. The practice of table salt iodization suggests that there is a risk of insufficient dietary iodine intake. Two urinary iodine concentrations of 72.27 and $57.23 \mu \mathrm{g} / \mathrm{l}$ were cited by Zou et al. [39] for urban and suburban population in the year 1995. The application of the equation above gave 1.0 and $1.3 \mu \mathrm{g} / \mathrm{kg} / \mathrm{day}$, respectively. A recent report from China states that 24 and $35 \%$ of the men and women, respectively, had thyroid nodules, an indicator of insufficient iodine intake [41] in areas where table salt was not iodized, suggesting that iodine intake was insufficient among general population even in coastal areas in China. Similarly, a publication on population in two regions in Nepal [42] reported low iodine intake levels; the GM levels were 3.14 and $2.62 \mu \mathrm{g} / \mathrm{kg} /$ day for men and women in one region, and 3.02 and $2.07 \mu \mathrm{g} / \mathrm{kg} /$ day in the other when body weights of 65 and
$53 \mathrm{~kg}$ were assumed for body weights of men and women, respectively [38].

The difference in iodine intake in China and Nepal from that in Japan and Korea may be due to different dietary habits in consumption of iodine-rich seaweed in daily life. With this regard, Suzuki and Tamura [43] measured UID in subjects after administration of seaweed-rich (i.e., highiodine) or seaweed-deleted (i.e., low-iodine) foods and found that UID varied in parallel to dietary iodine intake. The results are interesting in the sense that this observation appears to give direct evidence that seaweed is the major source of iodine. Unfortunately, these authors did not use alkali condition for digestion of urine samples and the possible loss of iodine from the digest cannot be ruled out. Thus, the study results may be evaluated only semiquantitatively.

There are several limitations in the present study. First of all, children studied were all from one prefecture of Miyagi although Japan consists of 47 prefectures. It is quite conceivable that food intake varies subject to local food habits. A nation-wide survey is apparently warranted.

The application of a conversion factor of 1.155 (Table 2) to estimate daily iodine intake from the calculated values which are based on the current FCT; the FCT is still incomplete with regard to iodine content information. The present analysis suggests that the conversion factor is proper and adequate (Table 2). Nevertheless, further efforts are apparently necessary to develop better estimation procedures.

To establish the factor, three cases were excluded as extreme values in the statistical analysis. A preliminary analysis of the food records revealed that the calculated values were substantially greater than the measured values in two children who took 'naga-kombu', a type of seaweed, and reverse was the case in the third child who took 'hijiki', another type of seaweed. It remained unclear; however, if the extreme values were associated with seaweed intake. Analyses for causative factor(s) were apparently warranted.

In conclusion within the limitations cited above, a method was developed to estimate dietary iodine intake (for all food items) from FCT-based calculated values despite the limitation that the iodine content data in the existing FCT do not cover all food items. Based on the method, the iodine intake for 3- to 6-year-old children in Miyagi prefecture, Japan, was $175 \mu \mathrm{g} /$ day with no difference between boys and girls. The iodine intake of the children was at the levels comparable to that of reported levels for adult Japanese population, when adjusted for body weight. Literature survey suggested that the levels both for children and adults in Japan may be somewhat higher than the intake in Korea, and substantially higher than the levels in China and Nepal. 


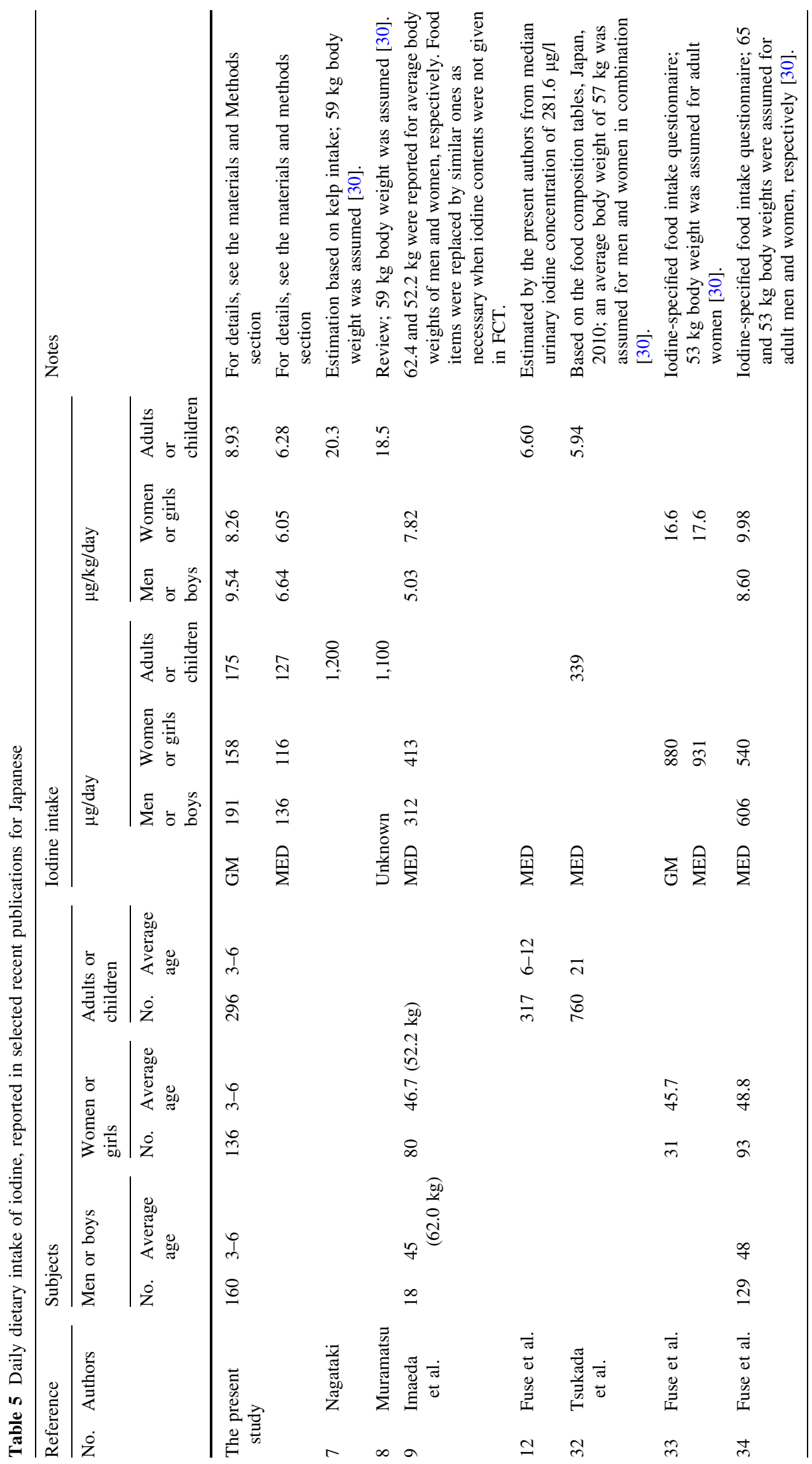


Acknowledgments The authors are grateful to the administrations and staff of the kindergartens participated in the study. Thanks are also due to the children and their guardians. This work was supported in part by Grants from the Ministry of Education, Culture, Sports, Science and Technology, Japan: Grant-in-Aid for Scientific Research C; 22500755 (Head Investigator; T. Watanabe for fiscal years 2010-2012) and Grant-in-Aid for Scientific Research C; 26350150 (Head Investigator; H. Nakatsuka for fiscal years 20114-16).

Conflict of interest The authors declare that they have no conflicts of interest.

\section{References}

1. Patrick L. Iodine; deficiency and therapeutic considerations. Altern Med Rev. 2008;13:116-27.

2. Akashi S, Hara T, Takamura N, Imaizumi M, Ashizawa $\mathrm{K}$, Akahoshi M, et al. Evaluation of thyroid function and iodine intake in Japanese young adults: preparation for prophylaxis of stable iodide during radiation emergency. Hiroshima J Med Sci. 2006;59:395-6 (in Japanese).

3. Takamura N, Hamada A, Yamaguchi N, Matsushita N, Tarasiuk I, Ohashi T, et al. Urinary iodine kinetics after oral loading of potassium iodine. Endocrine J. 2003;50:589-93.

4. Takamura N, Nakamura Y, Ishigaki K, Ishigaki J, Mine M, Aoyagi $\mathrm{K}$, et al. Thyroid blockade during radiation emergency in iodine-rich areas: effect of a stable-iodine dosage. J Radiat Res. 2004;45:201-4.

5. Atomic Energy Safety Committee (Working Group on the Treatment of the Exposed Subjects). Administration of stable iodine for the prevention of radiation-induced health effects at atomic plant emergency. (in Japanese) http://www.remnet.jp/ kakudai/o6/keylec.html Downloaded on 20 Mar 2013.

6. Michikawa T, Inoue M, Shimazu T, Sawada N, Iwasaki M, Sasazuki S, et al. Seaweed consumption and the risk of thyroid cancer in women: the Japan Public Health Center-based Prospective Study. Eur J Cancer Prev. 2012;21:254-60.

7. Nagataki S. The average of dietary iodine intake due to the ingestion of seaweeds is $1.2 \mathrm{mg} /$ day in Japan. Thyroid. 2008;18:667-8.

8. Muramatsu Y. Iodine: dietary and environmental considerations on iodine. Vitamins. 2012;86:558-61.

9. Imaeda N, Kuriki K, Fujiwara N, Goto C, Tokudome Y, Tokudome $\mathrm{S}$. Usual dietary intakes of selected trace elements $(\mathrm{Zn}, \mathrm{Cu}$, $\mathrm{Mn}, \mathrm{I}, \mathrm{Se}, \mathrm{Cr}$, and $\mathrm{Mo}$ ) and biotin revealed by a survey of fourseason 7-consecutive day weighed dietary records in middle-aged Japanese dietititians. J Nutr Vitaminol. 2013;59:281-8.

10. Guenther PM, Kott PS, Carriquiry AL. Development of an approach for estimating usual nutrient intake distribution at the population level. J Nutr. 1997;127:1106-12.

11. Fuse Y. Current medical topics and problems on iodine-An unique pattern of iodine nutrition in Japanese. Biomed Res Trace Elements. 2013;24:117-52 (in Japanese with English abstract).

12. Fuse Y, Saito N, Tsuchiya T, Shishiba Y, Irie M. Smaller thyroid volume with high urinary iodine excretion in Japanese schoolchildren: normative reference values in an iodine-sufficient area and comparison with the WHO/ICCIDD reference. Thyroid. 2007;17:145-55.

13. Ministry of Education. Culture, Sports, Science and Technology, Japan Standard Tables of Food Composition in Japan- 2010. Tokyo: Official Gazette Corporation of Japan; 2010 (in Japanese with English translation).

14. Ministry of Education, Culture, Sports, Science and Technology, Japan Notice on Standard Tables of Food Composition in Japan-
2010: Additions and Corrections. 11 Nov 2013 (in Japanese) http://www.mext.go.jp/b_menu/shingi/gijyutu/gijyutu3/houkoku/ 1298713.htm. Downloaded on 10 Jan 2014.

15. Nakatsuka H, Shimbo S, Watanabe T, Yaginuma-Sakurai K. IkedaM. Applicability of food composition tables as a tool to estimate mineral intake of preschool children in Japan: a validation study. J Trace Elem Med Biol. 2013;27:339-45.

16. Shimbo S, Watanabe T, Nakatsuka H, Yaginuma-Sakurai K, Ikeda M. Intake of tin from foods and drinks by preschool children in Japan. Environ Health Prev Med. 2013;18:230-6.

17. Watanabe T, Nakatsuka H, Shimbo S, Yaginuma-Sakurai K, Ikeda M. High cadmium and low lead exposure of children in Japan. Int Arch Occup Environ Health. 2013;86:865-73.

18. Fecher P, Goldmann I, Nagengast A. Determination of iodine in food samples by inductively coupled plasma mass spectrometry after alkaline extraction. J Anal Atom Spectromet. 1998;13:977-82.

19. Benkhedda K, Robichaud A, Turcotte S, Béraldin FJ, Cockell KA. Determination of total iodine in food samples using inductively coupled plasma-mass spectrometry. J AOAC Int. 2009;92:1720-7.

20. Romartís-Hortas V, Moreda-Piñeiro A, Bermejo-Barrera P. Microwave-assisted extraction of iodine and bromine from edible seaweed for inductively coupled plasma-mass spectrometry determination. Talanta. 2009;79:947-52.

21. Shelor CP, Dasgupta PK. Review of analytical methods for quantification of iosine in complex matrices. Anal Chim Acta. 2011;702:16-36.

22. Sullivan D, Zywicki R. Determination of total iodine in foods and dietary supplements using inductively coupled plasma-mass spectrometry. J AOAC Int. 2012;95:195-202.

23. Wang Y, Ou Y-L, Liu Y-O, Xie Q, Liu Q-F, Wu Q, et al. Correlations of trace element levels in the diet, blood, urine, and feces in Chinese male. Biol Trace Elem Res. 2012;145:127-35.

24. Acheson KJ, Campbell IT, Edholm OG, Miller DS, Stock MJ. The measurement of food and energy intake in man-An evaluation of some techniques. Am J Clin Nutr. 1980;33:1147-54.

25. Ministry of Education, Culture, Sports, Science and Technology, Japan Analysis Manual for food composition; iodine p. 476 and errata. 2005. (both in Japanese). http://www.mext.go.jp/compo nent/b_menu/shingi/toushin/_icsFiles/afieldfile/2012/10/15/ 1299052_2.pdf http://www.mext.go.jp/b_menu/shingi/gijyutu/ gijyutu3/houkoku/1298713.htm Downloaded on 27 Mar 2013.

26. Ichihara K. Smirnov's test for extreme value. In: Statistics for Bioscience. Tokyo, Japan: Nanko-do Publishers; 1995 (in Japanese).

27. Iyengar GV, Kawamura H, Parr RM, Miah FK, Wang JX, Dang HS, et al. Dietary intake of essential minor and trace elements from Asian diets. Food Nutr Bull. 2002;23(3 Suppl):124-8 (Errata 2002;23:431).

28. Iyengar GV, Kawamura H, Dang HS, Parr RM, Wang J, Akhtner $\mathrm{P}$, et al. Dietary intakes of seven elements of importance in radiological protection by Asian population; comparison with ICRP data. Health Phys. 2004;86:557-64.

29. Zimmermann MB, Hess SY, Molinari L, de Benoist B, Delange $\mathrm{P}$, Braverman LE, et al. New reference values for thyroid volume by ultrasound in iodine sufficient schoolchildren; a World Health Organization/Nutrition for health and development iodine deficiency study group report. Am J Clin Nutr. 2004;79:231-7.

30. Zava TT, Zava DT. Assessment of Japanese iodine intake based on seaweed consumption: a literature-based analysis. Thyroid Res. 2011;. doi:10.1186/1756-6614-4-14.

31. Ministry of Health, Labour and Welfare, Japan. Dietary reference intakes for Japanese. Tokyo p: Daiichi Shuppan Publishers; 2010. p. 237-41. (Appendix p. 49) (in Japanese).

32. Tsukada N, Urakawa Y, Yokoyama J, Tanaka H, Igarashi M. Dietary iodine intake in Japanese university students; data 
analysis based on the standard tables of food consumption in Japan (2010 version). J Jpn Soc Clin Nutr. 2013;35:30-8 (in Japanese with English abstract).

33. Fuse Y, Yamaguchi S, Yamaguchi M, Okayasu K, Uematsu Y, Ohashi T, et al. Development and validation of food frequency questionnaire for assessing iodine intake. J Jpn Soc Clin Nutr. 2011;32:147-58 (in Japanese with English abstract).

34. Fuse Y, Tanaka T, Arata N, Harada S, Ogawa H, Fuse Y, et al. Resources and intake of iodine in Japanese adult assessed by newly reviewed food frequency questionnaires. J Jpn Soc Clin Nutr. 2012;34:18-28 (in Japanese with English abstract).

35. Kim JY, Moon SJ, Kim KR, Sohn CY, Oh JJ. Dietary iodine intake and urinary iodine excretion in normal Korean adults. Yonsei Med J. 1998;39:355-62.

36. Sugita M, Tsuchiya K. Estimation of variation among individuals of biological half-times of cadmium calculated from accumulation data. Environ Res. 1995;68:31-7.

37. Kim EH, Choi T-I, Park YK. Dietary iodine intake and the association with subclinical thyroid dysfunction in male workers. Korean J Nutr. 2012;45:218-28 (in Korean with English abstract).
38. Ministry of Health, Labour and Welfare, Japan. The national health and nutrition survey in Japan 2010. Tokyo: Daiichi Shuppan Publishers; 2013. p. 86 (in Japanese).

39. Zou S, Wu F, Guo C, Song J, Huang C, Zhu Z, et al. Iodine nutrition and the prevalence of thyroid disease after salt iodization: a cross-sectional survey in Shanghai, a coastal area in China. PLoS ONE. 2012;7(7):e40718.

40. Food and Nutrition Board, Institute of Medicine, Iodine: dietary reference intakes. Washington: National Academy Press; 2001 264.

41. Chen Z, Xu W, Huang Y, Jin X, Deng J, Zhu S, et al. Associations of noniodized salt and thyroid nodule among the Chinese population; a large cross-sectional study. Am J Clin Nutr. 2013;98:684-92.

42. Parajuli RP, Uezaki M, Watanabe C. Diet among people in th Terai region of Nepal, an area of micronutrient deficiency. J Biosoc Sci. 2012;44:401-15.

43. Suzuki M, Tamura T. Iodine intake of Japanese male university students: urinary iodine excretion of sedentary and physically active students and sweat iodine excretion during exercise. J Nutr Sci Vitam. 1985;31:409-15. 